\title{
Review Article \\ Influence of Physicochemical Aspects of Substratum Nanosurface on Bacterial Attachment for Bone Implant Applications
}

\author{
Kun Mediaswanti \\ Engineering Faculty, Tribhuwana Tunggadewi University, Jalan Telaga Warna Blok C, Malang, Indonesia \\ Correspondence should be addressed to Kun Mediaswanti; kun.a.mediaswanti@gmail.com
}

Received 30 June 2016; Accepted 4 October 2016

Academic Editor: Paresh Chandra Ray

Copyright (C) 2016 Kun Mediaswanti. This is an open access article distributed under the Creative Commons Attribution License, which permits unrestricted use, distribution, and reproduction in any medium, provided the original work is properly cited.

Biofilm formation on implant materials is responsible for periprosthetic infections. Bacterial attachment is important as the first stage in biofilm formation. It is meaningful to understand the influence of nanostructured surface on bacterial attachment. This review discusses the influence of physicochemical aspects of substratum nanosurface on bacterial attachment.

\section{Introduction}

The health problems related to prosthetic infections are overwhelming. Periprosthetic infections are serious complications, leading to osteomyelitis, deep tissue infection, and chronic pain, which may result in implant failure. The cost related to implant-associated infection is an economic burden for society and the government. As an illustration, the periprosthetic joint infection revision cost in USA is around $\$ 566$ million annually, and it is expected to reach $\$ 1.62$ billion by 2020 [1]. The possibility of prosthetic infection events could be influenced by several risk factors, including preoperative risk factors (e.g., obesity, diabetes-mellitus), operative risk factors, and postoperative risk factors (e.g., postoperative wound complications, urinary tract infections, and allogenic blood transfusion). Joint replacement revision surgery is a surgery procedure that is performed after the primary surgery due to (i) implant loosening/lysis, (ii) infections, and (iii) pain. Revision surgery is usually more expensive and is occasionally more complex than the primary joint replacement surgery [2]. The therapy for periprosthetic infections may involve two-stage prosthetic exchange separated by six weeks of intravenous antibiotic therapy, which results in long term hospitalization and a cost almost 5 times higher than the primary surgery [3].
Studies of bacterial attachment to surfaces are intensively conducted in engineering, marine, environmental, and also biomedical implant device due to its negative implications. The attachment of bacteria to a biomedical implant is a crucial step in the pathogenesis of prosthetic infection. There are two sources: (a) direct contamination of the wound and implant surface during surgery and (b) hematogenous or lymphatic seeding from infections from other part of body [4]. Understanding the underlying factors influencing bacterial attachment as well as characteristics of nanocoatings is essential for exploring the pathway on producing an effective nanocoatings for bone implant applications. In this review the basic of bacterial attachment and infections, nanocoatings and factors that influenced bacterial attachment will be discussed.

\section{Osseointegration and Infections}

New implants may also come into contact with bacteria after implantation. Bacteria may come from skin or hematogenous spread and also from the implant. It is crucial to accelerate the osseointegration process before any bacterial adhesion occurs. The main underlying reason for tissue osseointegration to occur first is that implant materials generally become resistant to bacterial colonisation [5]. There will 
be competition between tissue cells and bacteria. Once bacteria are in contact with the implant surface, they build an extracellular matrix, secrete polysaccharides, and form a biofilm. The biofilm is a conducive medium for adhesion and acts as a protective barrier for microbes; thus infections are more likely to occur. It is difficult to cure this condition since it is not easy for antibiotics to penetrate biofilms. This type of infection can be prevented if the materials can be modified to induce antibacterial properties through silver and copper ion implantation or the incorporation of zinc oxide, antimicrobial peptide, and chitosan [6, 7]. Another alternative effort to prevent biofilm formation is functionalising surface using metallic nanoparticles and coating surface material with quaternary ammonium compounds and iodine. Studies reported that coating material with antibiotics, such as minocycline/rifampin, silver sulfadiazine-chlorhexidine, also reduced bacterial adhesion [8].

2.1. Nanocoatings. An ideal bone implant material should have osteoconductive, osteoinductive, and osseointegration ability [9]. Furthermore, other key criteria for implant performance include biocompatibility and mechanical compatibility. Metals, such as titanium (Ti) and tantalum (Ta), are excellent materials for bone implant applications and have been extensively used. This is attributed to their light weight, corrosive resistance, and bioinert nature. However, they usually lack sufficient osseointegration for implant longevity $[10,11]$. The implant material surface after implantation will directly contact with the host bone tissue. One way for improving the healing process is the application of a nanohydroxyapatite coating onto the surface of biomedical devices and implants. Hydroxyapatite (HA) belongs to the calcium phosphate family and demonstrates the best bioactivity amongst other forms of calcium phosphate. Hydroxyapatite exhibits functionality in promoting osteoblast adhesion, migration and differentiation, and proliferation, which are essential for bone regeneration. Most importantly, HA has the ability to bond directly onto bone. The hydroxyapatite (HA) layer was able to promote the biointegration process due to its ability to adsorb molecules of water and proteins, thus stimulating new bone tissue growth around the implant. In particular, nanocrystalline $\mathrm{HA}$ is more pertinent than microcrystalline HA because of its structural similarity with apatite [11, 12].

Surface modification is an important step in producing a long lasting bone implant due to the need to alter the surface physicochemical properties. During the past three decades, several techniques, such as sputtering, sol gel, chemical vapour deposition, and pulsed laser deposition, were used to produce nanoscale coatings with relative good quality. However, all these techniques have limitation in producing HA films with the desired stoichiometry and crystallinity [11]. Criteria on high quality nanocoatings on metallic substrates are excellent mechanical and bonding strength onto the substrates, hardness, and Young modulus that mimics human bone. A study reported that hydroxyapatite-silver coatings onto titanium reduced the number of bacteria adhered on its surface compared to noncoated titanium [13]. Similar results were reported by Mediaswanti et al.; $\mathrm{HA}-\mathrm{SiO}_{2}$ coated titanium surfaces showed lower number of $P$. aeruginos $a$ and S. aureus attached on the surfaces [14].

The hydroxyapatite coating thickness varies from nanometre scale up to micrometre scale. Hong et al. manufactured a $500 \mathrm{~nm}$ thick coating of crystalline HA using magnetron sputtering [15]. Mediaswanti et al. succeeded in producing $\mathrm{HA} / \mathrm{SiO}_{2}$ coatings with an average thickness of $200 \mathrm{~nm}$ [14]. Thian et al. succeeded in incorporating silicon in hydroxyapatite (Si-HA) using magnetron sputtering and discovered its potential use as a biocoating. The Si-HA film thickness was up to $700 \mathrm{~nm}$ [16]. To the best of the author knowledge, there was still lack of literature discussing bacterial attachment on nanocoatings.

2.2. Bacterial Attachment. Biofilm formation caused negative impacts on biomedical applications, as it leads to complicated infections. Prior to biofilm formation, the initial stage of the biological process is bacterial attachment. In this context, studies on bacterial attachment on various surfaces have been done intensively to obtain a surface that is able to resist bacterial retention on the surface, thus reducing biofilm formation. It has been proposed from rigorous studies that bacterial attachment on a surface is influenced by physicochemical, biological, and environmental parameters of the bacteria cells and the substratum surfaces. In this review, it will only discuss the influence of the physicochemical aspects (i.e., surface wettability, surface tension, surface topography, and surface charge) of the substratum surface on bacterial attachment.

2.3. Surface Wettability. The physicochemical properties of the surface play a significant role in bacterial attachment. Wettability is an interfacial property of a surface that influences the adhesion behaviour of biological cells. Surface wettability test is usually performed using contact angle measurement by sessile drop method. Measurement of contact angle with the surface is required to calculate the energy of the surface. Controlling the wettability of implant material surfaces is essential. Lower contact angle represents higher degree of wettability or hydrophilic surfaces; adversely higher contact angle indicates lower degree of wettability, which is known as hydrophobic.

Hydrophobic and hydrophilic surfaces are commonly defined as follows:

(i) Surfaces with water contact angle greater than $150^{\circ}$ are superhydrophobic.

(ii) Surfaces with water contact angle between $90^{\circ}$ and $150^{\circ}$ are hydrophobic.

(iii) Surfaces with water contact angle between $10^{\circ}$ and $90^{\circ}$ are hydrophilic.

(iv) Surfaces with water contact angle less than $10^{\circ}$ are superhydrophilic.

It was suggested that bacterial attachment is more prone to hydrophobic surfaces. Several studies revealed that the number of bacterial cells attached was higher on hydrophobic surfaces, as well as the rate of attachment [17]. Strength of bacterial binding was higher on the hydrophobic surface 
as reported in 1990 by Doyle and Rosenberg [18]. Marshall reported two stages of bacterial adhesion mechanism; at the beginning the adhesion was weak, and thus the bacteria were easily detached. In the next stage the adhesion was strong and irreversible by synthesis of extracellular biopolymer [19].

Van Loosdrecht et al. reported that entropy will increase as a result of displacement of inverse ordered layers of waters, which then creates a surface that is conducive for adhesion [20]. This phenomenon happened when two hydrophobic surfaces were approached to each other. In the case of hydrophilic surface, the surface attracts more water on its surface; thus, the adhesion was lower due to the necessity to remove the adsorbed water before adhesion takes place. Similar results on this phenomenon were also reported in numerous studies. Lower bacterial adhesion on less hydrophobic surfaces was reported by Li and Logan [21]. Bayoudh et al. produced an indium tin oxide coating on a glass. It was observed that the hydrophobic surfaces attracted more bacteria (S. epidermidis and P. stutzeri) to attach on its surfaces compared to bare glass [22]. In a study conducted by Chen et al., it was found that hydroxyapatitecoated titanium showed lower contact angle compared to the noncoated sample, exhibiting that coated titanium was less hydrophobic [13]. The number of bacteria adhered on the coated surfaces was less than the bare sample, indicating that less hydrophobic surface hinders bacteria attachment.

Much attention has been given in recent works on superhydrophobic type of surface because of their unique properties on self-cleaning effect and the interactions between materials and organism. Surfaces with water contact angle more than $150^{\circ}$ are superhydrophobic (i.e., nonwettability). It was reported that increasing the surface roughness will cause increase in contact angle and vice versa. It can be concluded that superhydrophobic surfaces have higher surface area due to the increase of surface roughness [23]. It is generally accepted that superhydrophobic surface has the ability to clean itself from contaminant due to low adhesion of water.

Fadeeva and coworkers produced a superhydrophobic surface on titanium that mimics a lotus leaf using femtosecond laser ablation technique and studied the bacterial adhesion on the surfaces. The surface consists of two-tier micro- and nanoscale structure (i.e., $200 \mathrm{~nm}$ wide irregular undulations). Two strains of bacteria, $P$. aeruginosa and $S$. aureus, were used. It was revealed that $P$. aeruginosa cells were unable to attach on the superhydrophobic surface, whereas S. aureus cells were observed on the surface [24]. On the contrary, another work related to superhydrophobic surface reported that $P$. aeruginosa cells were observed on the Cicada wings superhydrophobic surface [25].

2.4. Surface Tension. The surface energy and its component are a physicochemical aspect that influences bacterial attachment. There is fixed theory in regard to the effect of surface tension on bacterial attachment. Two different trends on the influence of surface energy were reported. It was reported that bacterial attachments decreased as the surface energy of substrate was larger $[26,27]$. Other studies reported opposite result; bacterial attachments were lower as the surface energy of the substrate decreases [28]. It can be concluded that no single factor determined bacterial attachment; other physicochemical properties of the substrate as well as the bacterial cells also play a role in bacterial adhesion.

2.5. Surface Topography. Surface topography is represented as surface roughness; it is defined as the irregular surface texture. Surface topography is one of the physicochemical properties that influence bacterial attachment. However, there are not many works that have been explored. Surface roughness exists in macro-, micro-, and nanoscale. Experimental techniques to observe and quantify surface roughness are atomic force microscopy (AFM) and profilometer. However, AFM is more prominent than profilometer in resulting high resolution (subnanometre) 3D-spatial images.

In addition, AFM is a nondestructive technique and has the ability to quantify the nanotopography of a surface. Parameters that can be quantified are average surface roughness $\left(R_{a}\right)$, root mean square (RMS), roughness $\left(R_{q}\right)$, maximum surface roughness $\left(R_{\max }\right)$, and skewness $\left(R_{\text {skw }}\right)$, kurtosis $\left(R_{\text {kur }}\right)$, and peak $\left(R_{\mathrm{pc}}\right)$ and valley $\left(R_{\mathrm{vc}}\right)$ counts. Skewness $\left(R_{\text {skw }}\right)$ and kurtosis $\left(R_{\text {kur }}\right)$ are the statistical distributions of roughness character. Skewness can be described as a measure of the symmetry of the height probability density function. Kurtosis is peakedness of the profile. A surface that is centrally distributed has a kurtosis value greater than 3 ; a surface that has a well spread out distribution has a kurtosis value of less than 3. Peak and valley counts are the number of discernible peaks and valleys, respectively [29]. To date there is no fixed agreement on whether surface roughness hinders or favours bacterial attachment as numerous studies reported conflicting results.

Studies have proposed that surface irregularities provide a higher available surface area for bacteria to adhere. These surface irregularities include pit, scratch, cracks, and groove and were believed to act as a nest for bacteria to reside. It is widely believed that surface roughness in the range of 1$1.5 \mu \mathrm{m}$ is prone to bacterial adhesion due to the similar size of the bacteria. Other studies reported that surface roughness above $0.2 \mu \mathrm{m}$ increases bacteria adhesion [29-31]. Much work has been conducted to support the claim that bacteria adhesion increases proportionally with the increase of surface roughness. In Mediaswanti et al.s study, they observed that the numbers of $S$. aureus and $P$. aeruginosa cells attached were increased with the increase of the surface microroughness [14]. This phenomenon was also observed in Jeyachandran et al.s study, which reported that rougher surfaces tend to favour bacterial adherence. This report showed that surface microroughness promoted bacterial attachment [32].

There have been numerous works that reported conflicting results in regard to the effect of surface topography on bacteria retention. Surface architecture with nanoscale roughness showed higher number of $S$. aureus and $P$. aeruginosa adhered onto equal channel angular pressing (ECAP) processed titanium surface [33]. Similar result was reported when bacteria cells were preferably attached on nanoroughness surface of glass [34]. 
Elena and coworkers investigated the influence of nanoscale roughness of titanium thin films surfaces on bacterial attachment. The titanium thin film thickness produced was 3,12 , and $150 \mathrm{~nm}$ with an average surface roughness $\left(R_{a}\right)$ of $1.47 \pm 0.21 \mathrm{~nm}, 0.95 \pm 0.01 \mathrm{~nm}$, and $0.64 \pm 0.02 \mathrm{~nm}$, respectively. In their work, additional parameters (i.e., skewness and kurtosis) were used to provide an in-depth nanoarchitectural profile and provide more information on surface morphology, due to the average surface roughness $\left(R_{a}\right)$ on 12 and $150 \mathrm{~nm}$ film being similar. Skewness $\left(R_{\text {skw }}\right)$ for 3, 12, and $150 \mathrm{~nm}$ was $1.2 \pm 0.1,1.0 \pm 0.2 \mathrm{~nm}$, and $2.3 \pm 0.1 \mathrm{~nm}$ and kurtosis $\left(R_{\mathrm{kur}}\right)$ of the thin film was $9.2 \pm 1.3,5.6 \pm 0.1$, and $36.7 \pm 1.1$, respectively. In the case of 12 and $150 \mathrm{~nm}$ film, the skewness and kurtosis were significantly different, indicating different surface nanoarchitecture. According to their study, the skewness indicates disproportionate number of peaks and all of the kurtosis were greater than 3 , indicating narrow height distribution with considerable number of sharp peaks and low valleys. They reported that, in the case of $S$. aureus cells, increasing cell numbers were found as the surface became smoother. The same trend was also observed for $P$. aeruginosa cells [29].

Thin film of silver with thickness of $3 \mathrm{~nm}$ and $150 \mathrm{~nm}$ was sputtered onto titanium and yielded average surface roughness of $1.4 \pm 0.2 \mathrm{~nm}$ and $0.8 \pm 0.1 \mathrm{~nm}$, respectively. Bacterial attachment of two pathogenic strains (S. aureus and $P$. aeruginosa) on these surfaces was studied. They reported that higher number of both two strains of bacteria cells was observed on the smoother surfaces [35]. These studies provide evidence that certain bacteria strains were prone to attach on smoother surface at nanoroughness scale. This finding is contrary to the initial statement in previous section that higher surface roughness is prone to attract more bacteria cells. In summary, topographical surface plays a significant role in controlling the attachment of bacteria; however no agreement can be drawn regarding the relative influences of the surface topography on the extent of bacterial attachment.

2.6. Surface Charge. Surface charge is one factor that influences bacterial attachment. It is widely known that most bacteria cells possess net negative charge due to the high amount of carboxyl $(-\mathrm{COOH})$, amino $\left(-\mathrm{NH}_{2}\right)$, and phosphate $\left(-\mathrm{PO}_{4}\right)$ groups [36]. Surface that is negatively charged hinders bacterial attachment and for surface that is positively charged will encourage bacteria cells to adhere on the surface. For example, E. coli, bacteria strain that is negatively charged, showed higher number of cells attached on a positively charged gold compared to negative or neutral surfaces. This can be explained due to the repulsive electrostatic forces [37]. A study conducted by Kenawy et al. reported that phosphonium group showed antibacterial effect [38]. Similar result of antibacterial activity was observed on positively charged quaternary ammonium salts and activated carbon. It can be said that negatively charged surfaces restrict the initial bacterial attachment, whereas the positively charged groups hinder the bacterial growth.

\section{Conclusions}

One of the primary goals of this review was to discuss the influence of physicochemical aspects of substratum nanosurface on bacterial attachment. The substratum physicochemical characteristics that were explored are surface wettability, surface charge, surface topography, and surface tension.

The surface wettability of the substratum has been shown to influence the bacterial attachment. It was reported that hydrophobic surfaces encourage bacterial adhesion. Numerous studies have shown that there may be a correlation between surface roughness and bacterial attachment. However, there is no agreement yet on the bacterial attachment pattern as there are contradiction results. Studies have reported the increased bacterial attachment on rougher surfaces, possibly due to the higher surface area, whereas, in relation with nanoscale roughness, the smoother surface may attract more bacteria adhesion. It is important to emphasize that surface charge of substratum and bacterial cells affects bacterial adhesion, as most of bacteria have negative surface charge and if they interacted with positive surface charge of substratum they may induce more bacteria attachment.

In conclusion, no single factor determined bacterial attachment; other physicochemical properties of the substrate as well as the bacterial cells also play a role in bacterial adhesion [37]. In addition, the bacteria showing different preferences to attach to certain surfaces provide more insight on surface characteristics that prevent bacteria adhesion. This insight may contribute on surface engineering area to reduce the risk of implant infections. In addition, it will motivate more studies to explore the possibilities of antibacterial coatings to prevent initial adhesion of bacteria onto metallic implants.

\section{Competing Interests}

The author declares that they have no competing interests.

\section{References}

[1] M. Abdel-Hady Gepreel and M. Niinomi, "Biocompatibility of Ti-alloys for long-term implantation," Journal of the Mechanical Behavior of Biomedical Materials, vol. 20, pp. 407-415, 2013.

[2] S. M. Kurtz, E. Lau, H. Watson, J. K. Schmier, and J. Parvizi, "Economic burden of periprosthetic joint infection in the united states," Journal of Arthroplasty, vol. 27, no. 8, pp. 61-65, 2012.

[3] L. Bernard, P. Hoffmeyer, M. Assal, P. Vaudaux, J. Schrenzel, and D. Lew, "Trends in the treatment of orthopaedic prosthetic infections," Journal of Antimicrobial Chemotherapy, vol. 53, no. 2, pp. 127-129, 2004.

[4] K. Merritt and Y. H. An, "Factors influencing bacterial adhesion," in Handbook of Bacterial Adhesion. Principles, Methods and Applications, Y. H. An and R. J. Friedman, Eds., Humana Press, Totowa, NJ, USA, 2000.

[5] Y. H. An, R. B. Dickinson, and R. J. Doyle, "Mechanisms of bacterial adhesions and pathogenesis of implant and tissue infections," in Handbook of Bacterial Adhesion. Principles, Methods and Applications, Y. H. An and R. J. Friedman, Eds., Humana Press, New Jersey, NJ, USA, 2000. 
[6] L. Zhao, P. K. Chu, Y. Zhang, and Z. Wu, "Antibacterial coatings on titanium implants," Journal of Biomedical Materials Research-Part B Applied Biomaterials, vol. 91, no. 1, pp. 470480, 2009.

[7] J. Venkatesan and S.-K. Kim, "Chitosan composites for bone tissue engineering-an overview," Marine Drugs, vol. 8, no. 8, pp. 2252-2266, 2010.

[8] M. Bosetti, A. Massè, E. Tobin, and M. Cannas, "Silver coated materials for external fixation devices: in vitro biocompatibility and genotoxicity," Biomaterials, vol. 23, no. 3, pp. 887-892, 2002.

[9] T. W. Bauer and G. F. Muschler, "Bone graft materials: an overview of the basic science," Clinical Orthopaedics and Related Research, no. 371, pp. 10-27, 2000.

[10] B. R. Levine, S. Sporer, R. A. Poggie, C. J. Della Valle, and J. J. Jacobs, "Experimental and clinical performance of porous tantalum in orthopedic surgery," Biomaterials, vol. 27, no. 27, pp. 4671-4681, 2006.

[11] K. Mediaswanti, C. Wen, E. P. Ivanova, C. Berndt, and J. Wang, "Sputtered hydroxyapatite nanocoatings on novel titanium alloys for biomedical applications," in Titanium AlloysAdvances in Properties Control, InTech, 2013.

[12] J. Dumbleton and M. T. Manley, "Hydroxyapatite-coated prostheses in total hip and knee arthroplasty," Journal of Bone and Joint Surgery-Series A, vol. 86, no. 11, pp. 2526-2540, 2004.

[13] W. Chen, Y. Liu, H. S. Courtney et al., "In vitro anti-bacterial and biological properties of magnetron co-sputtered silvercontaining hydroxyapatite coating," Biomaterials, vol. 27, no. 32, pp. 5512-5517, 2006.

[14] K. Mediaswanti, C. Wen, E. P. Ivanova et al., "Investigation of bacterial attachment on hydroxyapatite-coated titanium and tantalum," International Journal of Surface Science and Engineering, vol. 8, no. 2-3, pp. 255-263, 2014.

[15] Z. Hong, A. Mello, T. Yoshida et al., "Osteoblast proliferation on hydroxyapatite coated substrates prepared by right angle magnetron sputtering," Journal of Biomedical Materials ResearchPart A, vol. 93, no. 3, pp. 878-885, 2010.

[16] E. S. Thian, J. Huang, S. M. Best, Z. H. Barber, and W. Bonfield, "A new way of incorporating silicon in hydroxyapatite (SiHA) as thin films," Journal of Materials Science: Materials in Medicine, vol. 16, no. 5, pp. 411-415, 2005.

[17] H. J. Busscher and H. C. van der Mei, "Physico-chemical interactions in initial microbial adhesion and relevance for biofilm formation," Advances in Dental Research, vol. 11, no. 1, pp. 24-32, 1997.

[18] R. J. Doyle and M. Rosenberg, Microbial Cell Surface Hydrophobicity, American Society for Microbiology, Washington, DC, USA, 1990.

[19] K. C. Marshall, "Biofilms: an over-view of bacterial adhesion, activity and control at surfaces," ASM News, vol. 58, pp. 202207, 1992.

[20] M. C. M. Van Loosdrecht, J. Lyklema, W. Norde, and A. J. B. Zehnder, "Bacterial adhesion: a physicochemical approach," Microbial Ecology, vol. 17, no. 1, pp. 1-15, 1989.

[21] B. Li and B. E. Logan, "Bacterial adhesion to glass and metaloxide surfaces," Colloids and Surfaces B: Biointerfaces, vol. 36, no. 2, pp. 81-90, 2004.

[22] S. Bayoudh, A. Othmane, F. Bettaieb, A. Bakhrouf, H. B. Ouada, and L. Ponsonnet, "Quantification of the adhesion free energy between bacteria and hydrophobic and hydrophilic substrata," Materials Science and Engineering C, vol. 26, no. 2-3, pp. 300305, 2006.
[23] E. Bormashenko, T. Stein, G. Whyman, Y. Bormashenko, and R. Pogreb, "Wetting properties of the multiscaled nanostructured polymer and metallic superhydrophobic surfaces," Langmuir, vol. 22, no. 24, pp. 9982-9985, 2006.

[24] E. Fadeeva, V. K. Truong, M. Stiesch et al., "Bacterial retention on superhydrophobic titanium surfaces fabricated by femtosecond laser ablation," Langmuir, vol. 27, no. 6, pp. 3012-3019, 2011.

[25] E. P. Ivanova, J. Hasan, H. K. Webb et al., "Natural bactericidal surfaces: mechanical rupture of pseudomonas aeruginosa cells by cicada wings," Small, vol. 8, no. 16, pp. 2489-2494, 2012.

[26] D. P. Bakker, F. M. Huijs, J. De Vries, J. W. Klijnstra, H. J. Busscher, and H. C. Van Der Mei, "Bacterial deposition to fluoridated and non-fluoridated polyurethane coatings with different elastic modulus and surface tension in a parallel plate and a stagnation point flow chamber," Colloids and Surfaces B: Biointerfaces, vol. 32, no. 3, pp. 179-190, 2003.

[27] Y. Liu and Q. Zhao, "Influence of surface energy of modified surfaces on bacterial adhesion," Biophysical Chemistry, vol. 117, no. 1, pp. 39-45, 2005.

[28] M. A. Pereira, M. M. Alves, J. Azeredo, M. Mota, and R. Oliveira, "Influence of physico-chemical properties of porous microcarriers on the adhesion of an anaerobic consortium," Journal of Industrial Microbiology and Biotechnology, vol. 24, no. 3, pp. 181-186, 2000.

[29] E. P. Ivanova, V. K. Truong, J. Y. Wang et al., "Impact of nanoscale roughness of titanium thin film surfaces on bacterial Retention," Langmuir, vol. 26, no. 3, pp. 1973-1982, 2010.

[30] C. M. L. Bollen, P. Lambrechts, and M. Quirynen, "Comparison of surface roughness of oral hard materials to the threshold surface roughness for bacterial plaque retention: a review of the literature," Dental Materials, vol. 13, no. 4, pp. 258-269, 1997.

[31] C. M. L. Bollen, W. Papaioanno, J. Van Eldere, E. Schepers, M. Quirynen, and D. Van Steenberghe, "The influence of abutment surface roughness on plaque accumulation and peri-implant mucositis," Clinical Oral Implants Research, vol. 7, no. 3, pp. 201211, 1996.

[32] Y. L. Jeyachandran, S. Venkatachalam, B. Karunagaran et al., "Bacterial adhesion studies on titanium, titanium nitride and modified hydroxyapatite thin films," Materials Science and Engineering C, vol. 27, no. 1, pp. 35-41, 2007.

[33] V. K. Truong, R. Lapovok, Y. S. Estrin et al., "The influence of nano-scale surface roughness on bacterial adhesion to ultrafinegrained titanium," Biomaterials, vol. 31, no. 13, pp. 3674-3683, 2010.

[34] N. Mitik-Dineva, J. Wang, V. K. Truong et al., "Escherichia coli, Pseudomonas aeruginosa, and Staphylococcus aureus attachment patterns on glass surfaces with nanoscale roughness," Current Microbiology, vol. 58, no. 3, pp. 268-273, 2009.

[35] E. P. Ivanova, J. Hasan, V. K. Truong et al., "The influence of nanoscopically thin silver films on bacterial viability and attachment," Applied Microbiology and Biotechnology, vol. 91, no. 4, pp. 1149-1157, 2011.

[36] H. H. M. Rijnaarts, W. Norde, J. Lyklema, and A. J. B. Zehnder, "DLVO and steric contributions to bacterial deposition in media of different ionic strengths," Colloids and Surfaces B: Biointerfaces, vol. 14, no. 1-4, pp. 179-195, 1999.

[37] B. Gottenbos, D. W. Grijpma, H. C. Van Der Mei, J. Feijen, and H. J. Busscher, "Antimicrobial effects of positively charged surfaces on adhering Gram-positive and Gram-negative bacteria," Journal of Antimicrobial Chemotherapy, vol. 48, no. 1, pp. 7-13, 2001. 
[38] E.-R. Kenawy, F. I. Abdel-Hay, A. E.-R. R. El-Shanshoury, and M. H. El-Newehy, "Biologically active polymers. V. Synthesis and antimicrobial activity of modified poly(glycidyl methacrylate-co-2-hydroxyethyl methacrylate) derivatives with quaternary ammonium and phosphonium salts," Journal of Polymer Science, Part A: Polymer Chemistry, vol. 40, no. 14, pp. 2384-2393, 2002. 

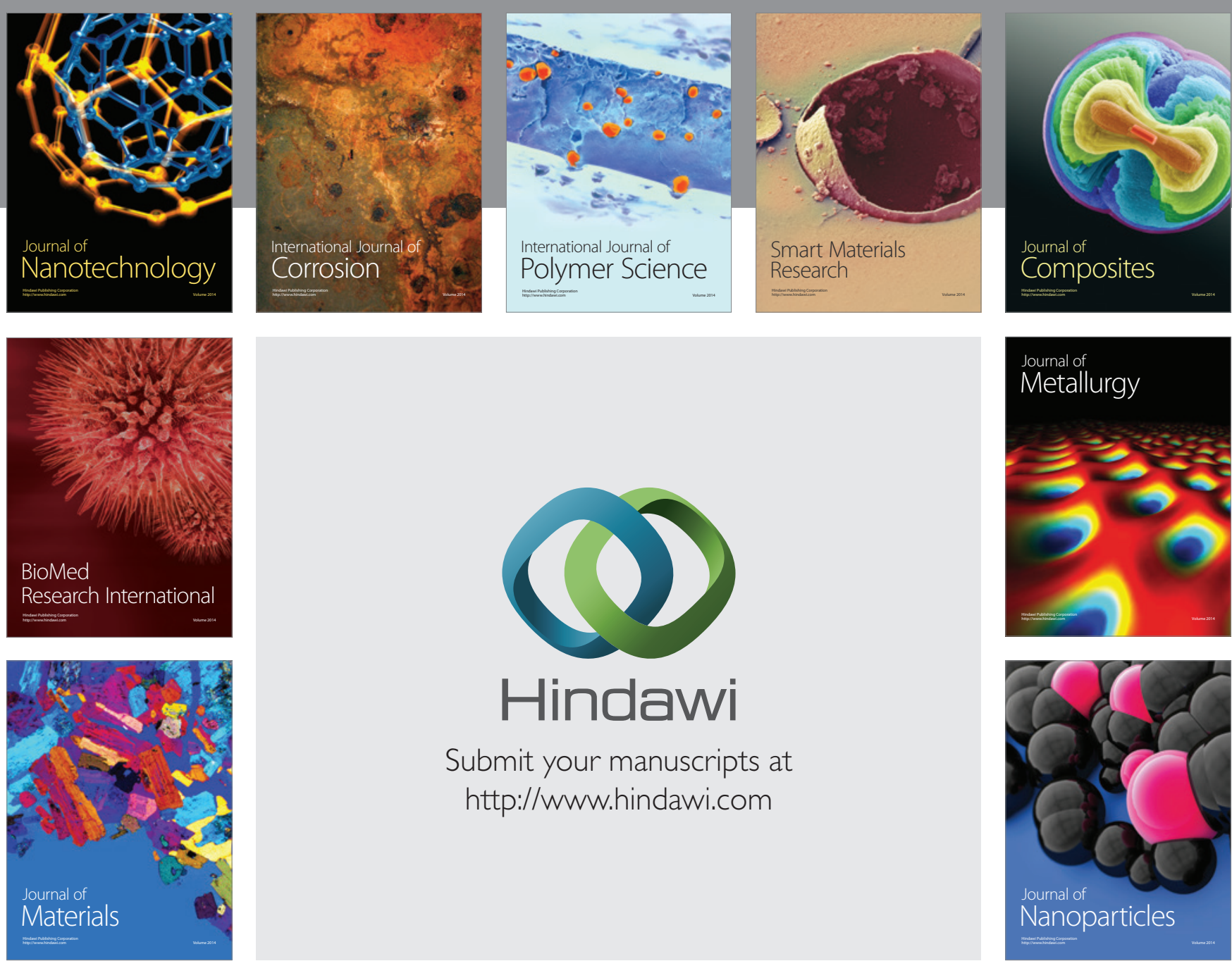

\section{Hindawi}

Submit your manuscripts at

http://www.hindawi.com

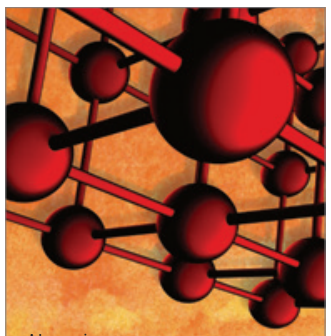

Materials Science and Engineering
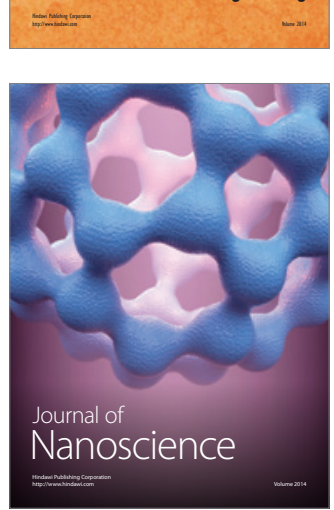
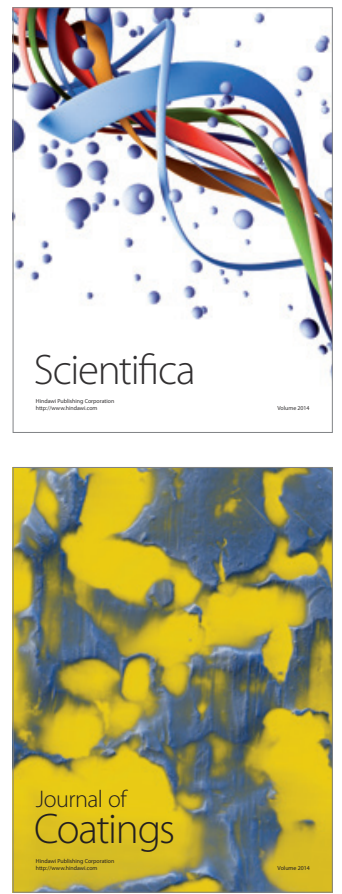
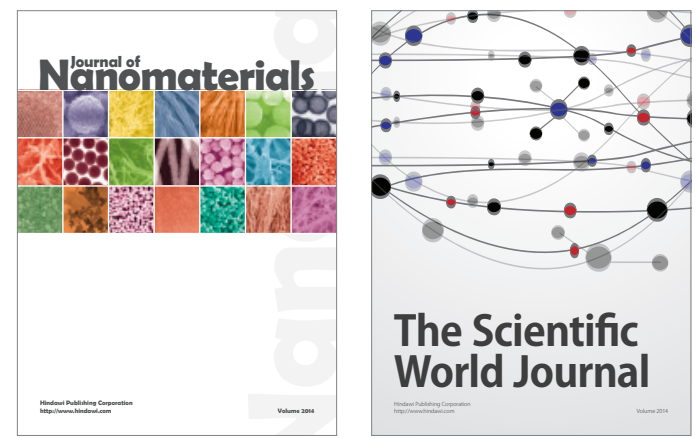

The Scientific World Journal
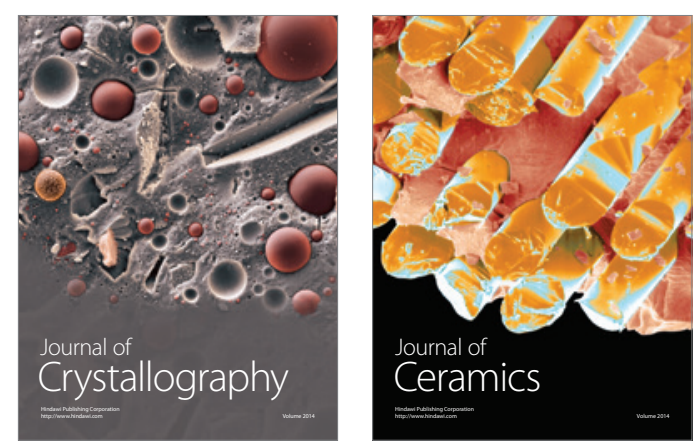
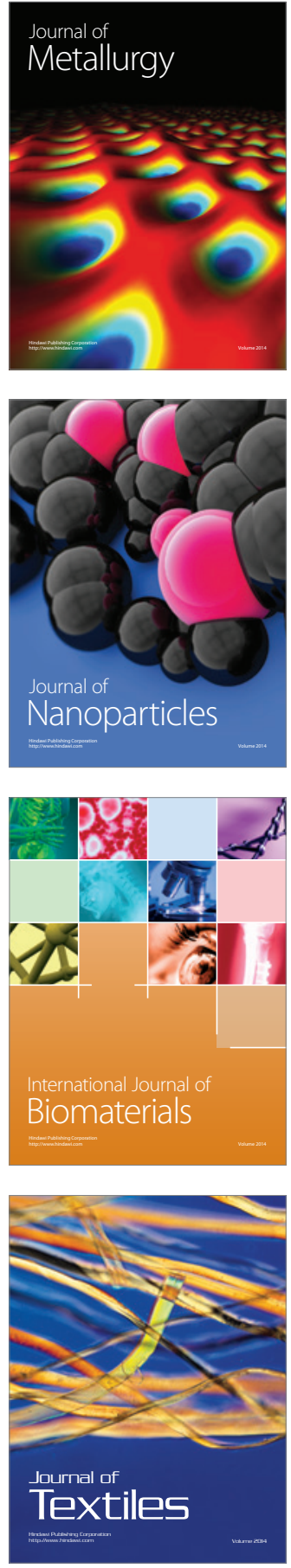